\title{
Comunicação
}

[Communication]

\section{Perfil sanitário e zootécnico de rebanhos caprinos nas microrregiões do Cariri paraibano}

\author{
[Sanitary profile of goat flocks in Cariri micro regions, \\ Paraiba State, Brazil] \\ D.A. Bandeira ${ }^{1} \dagger$, R.S. Castro $^{2}$, E.O. Azevedo ${ }^{3}$, L.S.S. Melo ${ }^{4}$, C.B. Melo ${ }^{4} *$ \\ ${ }^{1}$ Empresa de Pesquisa Agropecuária da Paraíba - João Pessoa, PB. \\ †in memoriam \\ ${ }^{2}$ Departamento de Veterinária - UFRPE - Recife, PE \\ ${ }^{3}$ Departamento de Veterinária - UFCG - Patos, PB \\ ${ }^{4}$ Faculdade de Agronomia e Medicina Veterinária - UnB \\ Campus Darcy Ribeiro, Asa Norte - ICC Sul \\ 70910-970 - Brasília, DF.
}

A caprinocultura leiteira sempre se apresentou, para a Paraíba e em especial para as microrregiões do Cariri, como uma atividade promissora. Contudo, a ocorrência de enfermidades, o baixo preço de venda e a má qualidade dos produtos oferecidos, além de grande exigência do mercado comprador, têm contribuído para o estrangulamento da atividade (Rodrigues e Quintans, 2003).

Considerando-se a queda na produção de leite, a perda de credibilidade do estabelecimento, as mortes de animais de alto valor zootécnico e os custos com assistência técnica, pode-se avaliar o impacto sobre a economia local, sobretudo nas situações em que a venda do leite representa a única fonte de renda familiar. Mais ainda, a agricultura familiar é a mais prejudicada (Azevedo et al., 2006).

Enfermidades como verminose, mamite, ectima contagioso, linfadenite caseosa, entre outras, têm sido observadas nessas regiões. O presente trabalho foi realizado com o objetivo de estudar o perfil sanitário e as características zootécnicas de rebanhos caprinos em fazendas nas microrregiões do Cariri, na Paraíba.
O estudo foi desenvolvido em 60 fazendas de caprinos, localizadas nas microrregiões do Cariri Ocidental e Oriental, na Mesorregião da Borborema da Paraíba, que está localizada na porção oriental da Região Nordeste. As fazendas amostradas estão localizadas nos municípios de São Sebastião do Umbuzeiro, São João do Tigre, Zabelê, Prata, Amparo, Monteiro, Prata, Sumé, Serra Branca, Cabaceiras, Boqueirão, Caturité, Taperoá, Santo André e Gurjão. Os rebanhos estudados são compostos, basicamente, por animais sem padrão racial definido para uma determinada exploração.

O tamanho da amostra foi determinado de acordo com Thrusfield (2004), com o total de 529 amostras, que resultou em 60 rebanhos usados neste estudo.

Para descrever o perfil sanitário nos rebanhos foi aplicado um questionário adaptado de Tinoco (1985). As principais características abordadas foram: relato e presença de enfermidades, infraestrutura no que se refere à divisão de piquetes, presença de maternidade, freqüência de assistência técnica, taxa de mortalidade e práticas de ordenha.

Recebido em 14 de agosto de 2006

Aceito em 5 de outubro de 2007

* Autor para correspondência (corresponding author)

E-mail: cristianomelo@unb.br 
Para a análise estatística dos resultados foi utilizado o teste de dispersão de freqüências $\chi^{2}$ (Sampaio 1998).

As taxas de mortalidade são apresentadas na Tab. 1, sendo evidenciada uma associação significativa $(\mathrm{P}<0,01)$ entre faixa etária $\mathrm{e}$ mortalidade.

Tabela 1. Taxa de mortalidade de animais jovens e adultos em fazendas de caprinos nas microrregiões do Cariri Ocidental e Oriental na Paraíba

\begin{tabular}{ccc} 
& \multicolumn{2}{c}{ Taxa de mortalidade } \\
\cline { 2 - 3 } Faixa etária & Até $20 \%$ & Acima de $20 \%$ \\
\hline Jovem & $20,0 \mathrm{a}$ & $80,0 \mathrm{a}$ \\
Adulto & $85,0 \mathrm{~b}$ & $15,0 \mathrm{~b}$
\end{tabular}

$\chi^{2}=48,25 ; \mathrm{P}<0,01$

Valores seguidos por letras diferentes na coluna diferem entre si pelo teste de $\chi^{2}$.
Nas fazendas, 93,3\% (56/60) dos produtores recebem alguma assistência técnica, sendo $51,8 \%$ delas realizadas por médicos veterinários e $28,5 \%$ por agentes de desenvolvimento rural (ADR), que são pessoas com formação primária, mas instruídas para o trabalho com os animais, com periodicidade semanal ou quinzenal em $76,8 \%$ dos casos. Nas propriedades, predominou a assistência pública em $85,7 \%$.

Quanto ao piso da área coberta do aprisco, predominou o não ripado em 90\% (54/60) das fazendas; fora do aprisco predominou o piso de chão batido em 55\% (33/60).

Em 71,7\% (43/60) dos rebanhos é administrado pelo menos um tipo de vacina e, mais ainda, 17 usam-na para prevenir uma doença, 13 para duas e 13 para três doenças. A vacina contra clostridioses era utilizada em 95,3\% (41/43) fazendas, a contra raiva em $65,1 \%(28 / 43)$ e a contra linfadenite caseosa em 30,2\% (13/43).

As práticas sanitárias adotadas são apresentadas na Tab. 2. Os problemas sanitários são apresentados na Tab. 3 .

Tabela 2. Práticas sanitárias adotadas em 60 rebanhos de caprinos nas microrregiões do Cariri Ocidental e Oriental na Paraíba

\begin{tabular}{lcc}
\hline \multicolumn{1}{c}{ Prática sanitária } & Número & $\%$ \\
\hline Separação de animais doentes & 55 & 91,7 \\
Limpeza de cochos e bebedouros periodicamente & 54 & 90,0 \\
Adoção de calendário profilático & 51 & 85,0 \\
Controle de endoparasitos & 50 & 83,3 \\
Marcação individual & 47 & 78,3 \\
Divisão de piquetes & 46 & 76,7 \\
Desinfecção de curral & 44 & 73,3 \\
Separação de animais por idade & 37 & 61,6 \\
Separação de animais por sexo & 37 & 61,6 \\
Utilização de esterqueira & 36 & 60,0 \\
Corte e desinfecção do umbigo do recém-nascido & 33 & 55,0 \\
Enterro ou cremação dos cadáveres & 25 & 41,7 \\
Utilização de maternidade & 25 & 41,7 \\
Separação de animais após vermifugação & 18 & 30,0 \\
Troca de piquetes após vermifugação & 16 & 26,7
\end{tabular}


Perfil sanitário e zootécnico...

Tabela 3. Problemas sanitários nas fazendas de caprinos nas microrregiões do Cariri Ocidental e Oriental na Paraíba

\begin{tabular}{lcccccc}
\hline & \multicolumn{6}{c}{ Grau de importância } \\
\cline { 2 - 7 } Doença/sinal clínico & \multicolumn{2}{c}{ Grande } & \multicolumn{2}{c}{ Pequeno } & \multicolumn{2}{c}{ Nenhum } \\
\cline { 2 - 7 } & $\mathrm{N}$ & $\%$ & $\mathrm{~N}$ & $\%$ & $\mathrm{~N}$ & $\%$ \\
\hline Aborto & 39 & 65,0 & 11 & 18,3 & 10 & 16,7 \\
Mamite & 36 & 60,0 & 9 & 15,0 & 15 & 25,0 \\
Artrite & 32 & 53,3 & 10 & 16,7 & 18 & 30,0 \\
Linfadenite & 31 & 51,7 & 17 & 28,3 & 12 & 20,0 \\
Ceratoconjuntivite & 30 & 50,0 & 20 & 33,3 & 10 & 16,7 \\
Ectima & 29 & 48,4 & 17 & 28,3 & 14 & 23,3 \\
Mí́ase & 28 & 46,6 & 16 & 26,7 & 16 & 26,7 \\
Ectoparasitose & 28 & 46,6 & 13 & 21,7 & 19 & 31,7 \\
Pneumonia & 27 & 45,0 & 18 & 30,0 & 15 & 25,0 \\
Diarréia & 21 & 35,0 & 20 & 33,3 & 19 & 31,7 \\
Sintoma nervoso & 18 & 30,0 & 14 & 23,3 & 28 & 46,7 \\
Pododermatite & 13 & 21,7 & 9 & 15,0 & 38 & 63,3 \\
\hline
\end{tabular}

Entre os entrevistados $73,3 \%(44 / 60)$ ordenham os animais e destes, apenas $2,3 \%(1 / 44)$ utilizam ordenhadeira mecânica. Quanto ao tipo de plataforma de ordenha, $54,5 \%$ possuem plataforma de madeira, e $46,5 \%$ de alvenaria; apenas $36,4 \%$ adotam linha de ordenha. Com relação à higienização de utensílios, mãos e úberes, $73,3 \%$ a realizam.

A alta mortalidade encontrada em propriedades do Nordeste, relatada por Pinheiro et al. (2001) e por Boer et al. (1986), foi a principal causa da baixa taxa de desfrute. Além disso, baixos índices produtivos observados em rebanhos nordestinos por Souza Neto et al. (1996) e Caldas (1989) resultaram de falhas de manejo, principalmente o sanitário, e foram conseqüência da falta de higiene nas instalações e falhas na aplicação de vermífugos e vacinas. Isto não foi observado neste estudo, pois os criadores informaram não ser importante os sinais relacionados à verminose, como diarréia e pneumonia. Acrescente-se que nas fazendas estudadas a maioria dos produtores adotava práticas de controle e combate à verminose, como limpeza periódica de cochos e bebedouros, realização de exames laboratoriais e vermifugação preventiva, mineralização do rebanho, uso de esterqueiras e manutenção de animais presos após a vermifugação. Isso provavelmente é reflexo do atendimento por algum tipo de assistência técnica, destacando-se a prestada pelo médico veterinário de forma quase contínua, com visitas semanais ou quinzenais. Apesar de declararem que a assistência técnica é pública, os produtores remuneram indiretamente os técnicos por meio das associações de caprinocultores locais, com um percentual pré-estabelecido da cota de leite.

As informações fornecidas por Avelino (2005) já indicavam redução nas taxas de mortalidade entre 2001 e 2004. Segundo o autor, cerca de $50,0 \%$ dos cabritos não sobreviviam aos 15 primeiros dias de vida na maioria dos criatórios e em algumas propriedades esse índice chegava a $100 \%$. Após a implantação de programas de ações mistas (governamentais e privadas), como o programa Pacto Novo Cariri e do projeto Leite da Paraíba, houve redução na taxa de mortalidade animal, em torno de $80 \%$ nas duas primeiras semanas após o parto e de $15 \%$ em relação ao rebanho em geral.

Diferentemente do que foi relatado por Tinoco (1985), Pinheiro et al. (2001) e Silva et al. (2005) na Bahia, Ceará e Rio Grande do Norte, respectivamente, a verminose não foi apontada como doença de grande importância e, ao contrário, aborto, mamite e artrite foram 
consideradas como as de maior relevância, destacando-se as duas primeiras por estarem relacionadas diretamente com a produção.

Dentre as práticas sanitárias adotadas observouse que a separação de doentes, a limpeza periódica de cochos e bebedouros, a adoção de calendário profilático e a desinfecção de currais após a vermifugação foram incorporadas como rotina na maioria dos criatórios. Entretanto, a rotação de piquetes para separação dos animais após vermifugação e o uso de maternidade não foram adotadas, muito provavelmente pela falta de organização gerencial das propriedades.

Igualmente ao descrito por Pinheiro et al. (2001), preocupante é o fato de que apenas 55,0\% dos criadores estudados realizam o corte $\mathrm{e}$ desinfecção do umbigo. No trabalho Boer et al. (1986) essa prática foi bastante utilizada.
As campanhas de vacinação e vermifugação promovidas pelo Governo do Estado permitiram maior acesso dessas práticas, ou seja, $71,7 \%$ das propriedades passaram a adotá-las, sendo a vacinação contra clostridioses a mais freqüente, seguida das vacinações contra a raiva e linfadenite caseosa.

Palavras-chave: caprino, perfil sanitário, doença

\section{AGRADECIMENTOS}

Ao Conselho Nacional de Desenvolvimento Científico e Tecnológico $(\mathrm{CNPq})$ pelo apoio financeiro. Os autores prestam homenagem póstuma ao Dr. Dimas Assis Bandeira, falecido recentemente de forma precoce.

\begin{abstract}
This work was performed in 60 goat farms located in 15 counties of the micro regions of Western and Eastern Cariri, in Paraiba, to describe and analyze the sanitary profile of the flocks. Visits were done and the answers, obtained from questionnaires that were applied to the farmers, were used. It was observed a mortality of $20 \%$ in young animals in $80 \%$ of the farms. The presence of technical assistance in $93.3 \%$ in the studied farms, adoption of prophylactic calendar in $85 \%$ and parasitic control in $83.3 \%$ of the flocks were also observed.
\end{abstract}

Keywords: goat, sanitary profile, disease

\section{REFERÊNCIAS BIBLIOGRÁFICAS}

AVELINO, R.Q. Estudo de caso: Caprinovinocultura no Cariri Paraibano. João Pessoa: SEBRAE-PB, 2005. 16p.

AZEVEDO, E.O.; ALCÂNTARA, M.D.B.; NASCIMENTO, E.R. et al. Contagious agalactia by Mycoplasma agalactiae in small ruminants in Brazil: first report. Braz. J. Microbiol., v.37, p.576-581, 2006.

BOER, A.J.; GUTIERREZ, A.; SOUZA NETO, J. Farmlevel resources for small ruminant production. In: REUNIÃO TÉCNICO-CIENTIIFICA DO PROGRAMA DE APOIO À PESQUISA COLABORATIVA DE PEQUENOS RUMINANTES, 1986. Sobral. Anais.. Sobral: Embrapa/CNPC, 1986. p.9-36.

CALDAS, E.M. Estudo da ovinocaprinocultura na região nordeste do estado da Bahia. Arq. Esc. Med. Vet UFBA, v.12, p.1-98. 1989.

PINHEIRO, R.R.; GOUVEIA, A.M.G.; ALVES, F.S.F. Prevalência da infecção pelo vírus da artrite encefalite caprina no estado do Ceará, Brasil. Cien. Rural, v.31, p.449-454, 2001.
RODRIGUES, A.; QUINTANS, L.J. Produção e beneficiamento do leite de cabra na Paraíba. In: SIMPOSIO INTERNACIONAL SOBRE CAPRINOS E OVINOS, 2., 2003, João Pessoa. Anais... João Pessoa, 2003. p.291-302.

SAMPAIO, I.B.M. Estatística aplicada à experimentação animal. 1.ed. Belo Horizonte: FEPMVZ, 1998. 221p.

SILVA, J.S.; CASTRO, R.S.; MELO, C.B. et al. Infecção pelo vírus da artrite-encefalite caprina no Rio Grande do Norte. Arq. Bras. Med. Vet. Zootec., v.57, p.726-731, 2005.

SOUZA NETO, J.; BAKER, G. A.; SOUSA, F. B. Caprinocultura de duplo propósito no Nordeste do Brasil: avaliação do potencial produtivo. Sobral: Embrapa Caprinos. p.210-212. 1996. (Relatório técnico do CNPC 1987-1995).

THURSFIELD, M. Epidemiologia veterinária. 2.ed. São Paulo: Roca, 2004. 572p.

TINOCO, A.L.A. Caracterização das formas de produção caprina da micro-região 138-Senhor do Bonfim, Bahia. 1985. 86f. Dissertação (Mestrado) Escola de Veterinária, Universidade Federal de Minas Gerais, Belo Horizonte, MG. 